also have somatostatin- ${ }^{19,20 ;}, \quad \gamma$-aminobutyric acid- ${ }^{21}$ and catecholamine-containing neurites ${ }^{22}$. It is probable that cholinergic deafferentation of the cortex (including the hippocampus) is an important contributor to the cognitive impairments of Alzheimer's disease. However, the hypothesis that subcortical cholinergic neurones, by virtue of their particular metabolism or other molecular specialization, are the primary focus of Alzheimer's pathology seems no longer tenable. If cholinergic subcortical degeneration is not the primary focus, it may reflect a disease process acting concurrently on diverse independent structures, or it may be the result of abnormalities of the target cortical regions. The latter possibility is compatible with observations that the neuronal loss in different parts of the cholinergic basal forebrain system in Alzheimer's disease is proportional to the extent of neuritic plaque formation in their respective cortical targets $^{23}$, and with the observation of degenerative changes in cholinergic neurones of the basal forebrain following cortical lesions in rats $^{24,25}$, monkeys and humans ${ }^{26}$.

1. Bowen, D.M. et al. Brain 99,459 (1976).

2. Davies, P. \& Moloney, J.F. Lancet ii, 1403 (1976)

3. Perry, E.K. et al. Lancet i, 189 (1977)

4. De Souza, E.B. et al. Nature 319, 593 (1986)

5. Bissette, G. et al. JAMA 254, 3067 (1985).

6. Vale, W.W. et al. Science 213, 1394 (1981)

7. Olschowka, J.A. et al. Neuroendocrinology 35, 305 (1982).

8. Swanson, L.W. et al. Neuroendocrinology 36, 165 (1983).

9. De Souza, E.B. et al. Science 224, 1449 (1984).

0. Davies, P. et al. Nature 288, $279(1980)$

11. Rossor, M. et al. Neurosci. Lett. 20, 373 (1980)

12. Beal, M.F. et al. Science 229, 289-291 (1985).

13. Roberts, G.W, et al. Nature 314, 92 (1985).

14. Arnsten, A.F.T. \& Goldman-Rakic, P.S. Science 230, 1273 (1985).

15. Rossor, M. Br. Med. J. 283, 1588 (1981).

16. Coyle, J.T. et al. Science 219, 1184 (1983)

17. Tomlinson, B.E. Pyschol. Med. 12, 449 (1982)

18. Kitt, C.A.et al. Science 226, 1443 (1984).

19. Struble, R.G. et al. Brain Res. 324, 394 (1984).

20. Morrison, J.H. et al. Nature 314, 90 (1985)

1. Walker, L.C. et al. Neurosci. Lett. 59, 165 (1985).

22. Kitt, C.A. et al. Neuroscience 16, 691 (1985).

23. Arendt, T. et al. Neuroscience 14, 1 (1985).

24. Sofroniew, M.V. et al. Brain Res. 289, 370 (1983).

25. Stephens, P.H. et al. J. Neurochem. 45, 1021 (1985)

26. Pearson, R.C.A. et al. Brain Res. 261, 321 (1983).

Alan Fine is in the MRC Molecular Neurobiology Unit, University of Cambridge Medical School, Hills Road, Cambridge CB2 2QH, UK.

\title{
Atmospheric chemistry
}

\section{Reservoir species discovered in the stratosphere}

\section{from Donald J. Wuebbles}

IT is now recognized from theoretical models that several trace constituents of the stratosphere affect the distribution of ozone. But because of difficulties in achieving enough sensitivity, the stratospheric concentrations of many of these species, particularly those termed 'reservoir' species, have remained unobserved. Now, Toon et al., on page 570 of this issue $^{1}$, report the first conclusive measurement of the reservoir species $\mathrm{N}_{2} \mathrm{O}_{5}$.

Reservoir species are those trace constituents, such as $\mathrm{HNO}_{3}, \mathrm{HCl}, \mathrm{N}_{2} \mathrm{O}_{5}$ and $\mathrm{ClONO}_{2}$, that are produced from the more reactive ozone-destroying species, but are longer-lived and less reactive. In a sense, these gases act as temporary reservoirs or holding tanks for the more reactive ozonedestroying forms of nitrogen-, chlorineand hydrogen-containing species in the stratosphere. Of these reservoir species, only $\mathrm{HNO}_{3}$ and $\mathrm{HCl}$ have been measured extensively. The concentration distribution observed by Toon et al. applies only to a particular latitude and longitude on a single day, but nonetheless represents an important step towards the validation of key aspects in the theory of ozonecontrolling mechanisms.

Many recent studies have concerned the possibility that increasing concentrations of trace-gas emissions caused by human use, such as methane, nitrous oxide $\left(\mathrm{N}_{2} \mathrm{O}\right)$ and chlorocarbons (particularly $\mathrm{CFCI}_{3}$ and $\mathrm{CF}_{2} \mathrm{Cl}_{2}$ ) affect the distribution of stratospheric ozone. These trace gases, although emitted at the Earth's surface, are sufficiently long-lived to be transported to the upper atmosphere, where they dissociate into by-products that can

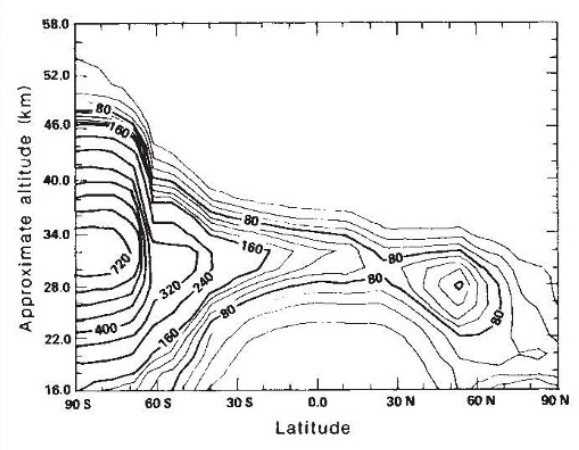

Two-dimensional model simulation of the latitudinal variation in $\mathrm{N}_{2} \mathrm{O}_{5}$ concentrations determined for May at local noon. By definition, the mixing ratio is the concentration divided by the air density. From the model of S. Solomon and R. Garcia.

react with ozone catalytically. The rate of conversion of the reactive species to the less-reactive, reservoir species largely determine the ultimate effect of these trace gases on stratospheric ozone. It has been noted that model-derived concentrations of the reservoir species are particularly sensitive to remaining uncertainties in atmospheric chemical reaction rates. For all these reasons, it was essential to measure the concentrations of reservoir species in the stratosphere.

$\mathrm{N}_{2} \mathrm{O}_{5}$ has long been thought to be important in the diurnal variation of $\mathrm{NO}_{2}$, which reacts with ozone. The slow photolysis of $\mathrm{N}_{2} \mathrm{O}_{5}$ should produce $\mathrm{NO}_{2}$ slowly during the day, while production of $\mathrm{N}_{2} \mathrm{O}_{5}$ should reduce $\mathrm{NO}_{2}$ concentrations slowly in the night-time stratosphere. Observations of the sunrise-sunset differences in the $\mathrm{NO}_{2}$ profile $^{2,3}$ and a recent analysis ${ }^{4}$ of satelliteobserved $\mathrm{NO}_{2}$ at varying zenith angles have tended to verify the importance of this process. The observations by Toon $e t$ $a l .{ }^{1}$ are in general agreement with the expected diurnal behaviour of $\mathrm{N}_{2} \mathrm{O}_{5}$.

Model calculations suggest that $\mathrm{N}_{2} \mathrm{O}_{5}$ concentrations are particularly large in the high-latitude winter (especially in the Arctic) and that $\mathrm{N}_{2} \mathrm{O}_{5}$ is the major portion of total reactive nitrogen in the high-latitude stratosphere (see figure). Trajectory analyses $^{5}$ suggest that the conversion of $\mathrm{NO}_{2}$ to $\mathrm{N}_{2} \mathrm{O}_{5}$ in the winter polar night explains the so-called Noxon cliff, in which sharp gradients in the total vertical column content of $\mathrm{NO}_{2}$ are observed at high latitudes. Measurements of $\mathrm{N}_{2} \mathrm{O}_{5}$ concentrations in the polar winter stratosphere in tandem with further observations of $\mathrm{NO}_{2}$ concentrations are needed to test this suggestion. In addition, heterogeneous mechanisms $s^{6}$ have been proposed for the conversion of $\mathrm{N}_{2} \mathrm{O}_{5}$ to $\mathrm{HNO}_{3}$ in the arctic winter. This could also be tested by observations of $\mathrm{N}_{2} \mathrm{O}_{5}$.

The observed profile of $\mathrm{N}_{2} \mathrm{O}_{5}$ in Toon et al.'s study is in general agreement with the expected theoretical distributions determined with models such as the Lawrence Livermore National Laboratory onedimensional model, but a direct comparison depends on knowing the $\mathrm{NO}_{2}$ and $\mathrm{O}_{3}$ concentrations at the same location. As the measurements of Toon et al. depend on assumed profile shape, the next step is to reduce this dependence. Clearly, based on the expected diurnal behaviour and from results (see figure) that show the strong winter high-latitude gradients, observations of $\mathrm{N}_{2} \mathrm{O}_{5}$ are needed at a wide range of seasons and locations, as well as at various times throughout the day, to validate the theory.

\footnotetext{
1. Toon, G.C., Farmer, C.B. \& Horton, R.H. Nature 319, 570 (1986).

2. Noxon, J.F., Whipple, E.C. \& Hyde, R.S. J. geophys. Res. 84, 5047 (1980).

3. Kerr, J.B., McElroy, C.T. \& Evans, W.R.J. Can. J. Phys. 60, 196 (1982).

4. Solomon, S. \& Russell, J.M. J. geophys. Res. (in the press). 5. Solomon, S. \& Garcia, R. J. geophys. Res. 88, 5497 (1983).

6. Evans, W.F.J., McElroy, C.T. \& Galbally, I.E. Geophys. Res. Lett. 12825 (1985).
}

Donald J. Wuebbles is in the Atmospheric and Geophysical Sciences Division, Lawrence Livermore National Laboratory, Livermore, California 94550, USA. 